\title{
Colaboração e participação de crianças no atendimento fonoaudiológico
}

\section{Collaboration and Participation of Children in Speech Therapy Care}

Camila Lima N ascimento ${ }^{1}$

Cecília Guarnieri Batista ${ }^{1}$

Gustavo Sátollo Rolim ${ }^{2}$

Antônio Bento Alves de M oraes ${ }^{2}$
${ }^{1}$ Departamento de

Desenvolvimento Humano eReabilitação, Faculdadede Ciências M édicas,

Universidade Estadual de Campinas. RuaTessália

Vieira de Camargo 126, Barão Geraldo. 13084-971

Campinas SP.

cecigb@fcm.unicamp.br

${ }^{2}$ Departamento de

Odontologia Social,

FaculdadedeOdontologia

dePiracicaba, Universidade

Estadual deCampinas
Abstract Situations of non-cooperation/participation of the patient are detected in healthcare, In many cases, it is impossible to complete the assessment procedures, and procedures of intervention may beprejudiced. This problem has been researched in some health areas, however there are few studies involving activities in Speech Therapy. The scope of this study was to conduct a survey of knowledge and strategies of Speech Therapists when faced with situations considered difficult in clinical practice with children. Semistructured interviews were staged with students and teachers of an undergraduate course in Speech Therapy at a Brazilian public university, addressing problems encountered in caring for children 4 to 12-year-olds, as well as proposed solutions. Analysis of content of the data involved the construction of a system of categories of reported and proposed strategies. The categories werecompared with those obtained in an analogous survey $(\mathrm{Pe}$ diatric Dental care) and the analysis highlighted specifics of care of each of the professions. The results contributed to the systematization of knowledge relating to collaboration/participation, and revealed the concern of the participants with the humanization of care.

Key words Professional-patient relationship, Collaboration/participation, Speech therapy
Resumo N os atendimentos em saúde, observamse situações de não colaboração/participação do paciente. Em muitos casos, não se consegue completar procedimentos de avaliação, e os procedimentos deintervenção podem ser prejudicados. Esse problema tem sido pesquisado por algumas áreas da saúde, sendo escassos os trabalhos envolvendo a atuação em Fonoaudiologia. 0 objetivo do presente estudo foi realizar um levantamento sobre conhecimentos eestratégias dos fonoaudiólogos diante de situações consideradas difíceis na prática clínica com crianças. Foram realizadas entrevistas semi estruturadas com estudantes e docentes de um curso de graduação em Fonoaudiologia deuma universidade pública brasileira, abordando problemas encontrados no atendimento de crianças de 4 a 12 anos, bem como as soluções propostas. A análise de conteúdo dos dados envolveu a construção deum sistema de categorias relativo às estraté gias relatadas epropostas. As categoriasforam comparadas com as obtidas em estudo análogo (atendimento em Odontopediatria), e a análise apontou para especificidades do atendimento em cada uma das profissões. Os resultados contribuíram para a sistematização do conhecimento relacionado à colaboração/participação, e evidenciaram a preocupação dos participantes com a humanização do atendimento.

Palavras-chave Relação profissional-paciente, Colaboração/participação, Fonoaudiologia 


\section{Introdução}

As profissões da área da saúde apresentam uma especificidade importante por terem como objetos de estudo e de trabal ho outros seres humanos, implicando no estabelecimento de relações humanas diferenciadas entre profissionais e clientes, entre os próprios profissionais, e entre estes profissionais e a família do cliente. Comumente é designada como relação profissionalpaciente, embora, mais recentemente, venha sendo criticado o termo "paciente" pela conotação de passi vidade inerente que carrega.

Nos atendimentos em saúde, sabe-se da existência de situações nas quais o profissional encontra dificuldade para obter a colaboração de seu paciente. A literatura recente ${ }^{1}$ faz uma distinção entre os termos "colaboração" e "participação", ambos utilizados no contexto de uma busca por uma relação profissional-paciente diferente da tradicional, emais humanizada. N o contexto da Enfermagem, Sahlsten et al. apresentam a distinção e a relação entre os termos "colaboração do paciente", "participação do paciente" e "parceria com o paciente". Para esses autores, a "colaboração do paciente", primeiro termo a ser utilizado para abordar a questão, consiste na permissão de realização do procedimento em questão, dependendo detroca deconhecimentos entre o profissional eo paciente, eda atenção do profissional ao que o paciente está dizendo. Em seguida, foi proposto o termo "participação", que supõe um envolvimento do paciente no seu tratamento, e mai or troca de conhecimentos entre o profissional e o paciente que no caso anterior. Dessa forma, a "partici pação do paciente" abrange um envolvimento do paciente no seu próprio atendimento: 0 paciente emite suas opiniões e participa das decisões relativas ao atendimento. Já o termo "parceria" é proposto como um ideal a ser buscado, que exige uma eqüidade dentro da relação profissional-paciente, e só é possível de pois que forem alcançadas a colaboração ea participação do paciente ${ }^{1}$.

Todos os aspectos referentes à relação profissional-pacientetornam-seainda mais relevantes quando se trata de crianças. Existe um interesse crescente por parte dos profissionais de saúde em maneiras de envolvêlas no tratamento, e com isso foi suscitada a necessidade de conhecer a opinião delas quanto ao seu tratamento ${ }^{2}$. Podese dizer que, também no contexto da atenção a crianças, há uma busca por uma relação a mais próxima possível da "parceria". Entretanto, há necessidade de discussão sobre os modos de se efetivar esse ideal, dependendo da idade da criança e dos procedimentos de saúde em questão.

A O dontologia é uma das profissões quetraz contribuiç̧ões para o tema das relações profissionais em saúde, especialmente no que tem sido abordado como a não-colaboração de crianças durante o tratamento. É possível encontrar estu$\operatorname{dos}^{3-7}$ que descrevem diferentes estratégias para a obtenção da colaboração, e que trazem a sugestão de procedimentos que incentivam comportamentos colaborativos, como um meio para alcançar o sucesso do atendimento. Além disso, foi avaliada a percepção de estudantes de 0 dontologia, quanto às suas habilidades para lidar com situações de não colaboração no atendimento, por parte de crianças. ${ }^{8}$ Um questionário composto por 10 situações-problema no atendimento odontológico foi aplicado em estudantes de Odontologia de duas universidades públicas brasilei ras. Para cada questão, o participante deveria assinalar seu nível de autoconfiança frente á situação apresentada e responder à questão aberta: "Como você lidaria com essa situação?". 0 estudo trouxe indicações sobreáreas focais na formação do estudante, de forma a melhor prepará-lo para esse tipo de problema.

Outra profissão da área da saúde que depende de colaboração/participação de crianças para o sucesso dos procedimentos de avaliação ou intervenção éa Fonoaudiologia?. Entretanto, são raros na literatura trabalhos que abordam especificamente a questão da colaboração/participação do paciente na prática fonoaudiológica.

Entre os trabal hos sobre o tema, Cupello aborda a questão da relação terapeuta-paciente e apresenta questões sociais e psicológicas que influenciam na atuação fonoaudiológica. Para a autora, essa atuação, em seus aspectos técnicos, dificilmente terá resultados se não houver respeito, conhecimento e busca das nuances inerentes às relações humanas.

M artins aborda a questão dentro da temática das experiências de estágio dos estudantes de Fonoaudiologia em clínica-escola, afirmando que a colaboração/participação da criança e da família no atendimento repercutem na maneira de agir do estagiário ${ }^{10}$.

N os livros clássicos nas áreas de motricidade orofacial ${ }^{11}$, de voz ${ }^{12}$, e de audiologia infanti ${ }^{13,14}$, os autores abordam a temática da colaboração/ participação, evidenciando sua importância para o sucesso da intervenção/avaliação fonoaudiológica.

A literatura sobre o tema não é extensa, e discute a necessidade de obtenção da colaboração/ 
participação, especialmente no que se refere às crianças, nas diferentes áreas de atuação da Fonoaudiologia. Além disso, a vivência da formação de estudantes de graduação em clínicas-escola mostra as dificuldades para a realização de procedimentos de avaliação eterapia, no caso de crianças não colaboradoras. Tendo em vista a carência de trabalhos na área, surge a questão: quais são e como são enfrentadas as situações consideradas difíceis no atendimento fonoaudiológico de crianças?

\section{Objetivos}

O objetivo do estudo foi realizar um levantamento sobre conhecimento e estratégias dos fonoaudiólogos para lidar com situações consideradas difíceis na sua prática clínica, com crianças nafaixa etária de quatro a doze anos de idade. Para tanto, o estudo compreendeu a tar efa de identificar as situações consideradas difíceis e as formas de obtenção de colaboração/participação na prática clínica, a partir de dois tipos de relato: a) experiências deestudantes degraduação em Fonoaudiologia; b) docentes das áreas deAudiologia, Linguagem, M otricidade O rofacial e Voz. No que se refere às formas de obten ção de colaboração/participação, buscou-se, também, comparar os conjuntos deestratégias obtidas no estudo sobreatendimento odontopediátrico ${ }^{8}$ com as respostas ao presente estudo.

\section{Métodos}

0 estudo foi do tipo transversal, com realização de pesquisa bibliográfica e análise de dados coletados, com aprovação no Comitê de Ética da Faculdade de Ciências M édicas da Universidade Estadual de Campinas.

\section{Participantes}

Foram incluídos como sujeitos da pesquisa ${ }^{15}$ estudantes do 40 ano de um curso de Fonoaudiologia de uma universidade pública da região sudeste, e quatro docentes que atuavam nas diferentes áreas da Fonoaudiologia, a saber: Audiologia, Linguagem, M otricidadeO rofacial eVoz.

Os participantes foram voluntários e assinaram o Termo de Consentimento Livre e Esclarecido.

\section{Procedimento de coleta de dados}

A coleta de dados foi real izada através de uma entrevista semiestruturada abrangendo os seguintes tópicos: problemas encontradosno atendimento fonoaudiológico de crianças de quatro a doze anos, soluções propostas para esses problemas e fundamentos para a escolha dessas soluções.

As entrevistas foram realizadas em um serviço de uma universidade pública que inclui uma clínica-escola de Fonoaudiologia. Os participantes foram entrevistados um a um, em uma sala de atendimento, e a entrevista foi gravada com um gravador de voz, para posterior transcrição dos dados para análise.

Procedimento de análise de dados

Depois da leitura das transcrições das entrevistas, foi realizada a análise de conteúdo dos dados $^{15}$. Um sistema de categorias foi construído com base nos objetivos do estudo, com modificação de um sistema de categorias relativo a modos de lidar com situações de não colaboração em odontopediatria ${ }^{8}$, de forma a adequá-lo à área da Fonoaudiologia.

A partir da categorização das respostas, foram realizadas as seguintes análises: a) comparação das categorias encontradas no presente estudo com as categorias encontradas no estudo da Odontologia, b) organização de um panorama das situações que trazem mais dificuldade no atendimento fonoaudiológico, ec) levantamento da origem das estratégias utilizadas diante de situações de não-colaboração no atendimento fonoaudiológico (somente para os participantes estudantes).

As respostas dos estudantes foram organizadas de acordo com a origem da estratégia (experiência pessoal, experiência relatada por colega e orientações de supervisores e professores) para cada área de atuação abordada nesse estudo (Audiologia, Linguagem, Motricidade Orofacial e Voz). Já as respostas dos docentes foram organizadas por: situações que trazem dificuldade ao atendimento fonoaudiológico, soluções para lidar com essas situações, e orientações dadas aos alunos em supervisão de estágio. 
Resultados

Comparação das categorias encontradas no estudo da O dontologia

com as categorias encontradas

no presente estudo

O Q uadro 1 apresenta a fusão dos sistemas decategorias do estudo de O dontologia edo presente estudo.

$\mathrm{Na}$ leitura das respostas, foram encontradas diferenças nas fornecidas pelos estudantes de Fonoaudiologia em relação às dos estudantes de
Odontologia, e foram elaboradas mudanças no sistema de categorias utilizado como base para o sistema do presente estudo. As mudanças envolveram inclusão, modificação, supressão e manutenção de categorias, a saber:

- Categorias retiradas/modificadas:

* subcategorias da categoria Explicação: na Odontologia existem mais procedimentos específicos a serem explicados, eisso abre a possibilidade de diversos modos de explicar. Além disso, existe nos manuais de 0 dontopediatria a estratégia Conte-M ostra-Faça.

* categoria Comando: em Odontologia, como forma de lidar com a situação, surgem os co-

\begin{tabular}{|c|c|c|}
\hline Tipo & Categoria & Subcategoria \\
\hline Instrucionais (INSTR) & $\begin{array}{l}\text { Comando (COM) ODONTo } \\
\text { Explicação (EXPL) ODONTo } \\
\text { Explicação (EXPL) (genérica) FONo } \\
\text { Representação/demonstração (REPRES) }\end{array}$ & $\begin{array}{l}\text { Expl. A ODONTO } \\
\text { Expl. B ODONTO } \\
\text { Expl. C ODONTO } \\
\text { Expl. D ODONTO }\end{array}$ \\
\hline Persuasivas (PERS) & $\begin{array}{l}\text { Tranquilização (TRANQ) FONO + ODONTO } \\
\text { Controle parcial pela criança (CONT) FONO + ODONTO } \\
\text { Oferta de recompensa (OF) FONO + ODONTO } \\
\text { Tentativa de convencimento (CONV) } \\
\text { Estratégia lúdica (ESTR LÚ DICA) FONO } \\
\text { Encorajamento da cooperação (COOP) FONo }\end{array}$ & \\
\hline Restritivas (REST R) & $\begin{array}{l}\text { Ameaça/censura } \\
\text { Restrição de mobilidade }\end{array}$ & $\begin{array}{l}\text { Censura (CENS) FONO + ODONTO } \\
\text { Ameaça/demonstração de autoridade } \\
\text { (AM) FONO + ODONTO } \\
\text { Inespecífica ODONTO } \\
\text { Ignorar manifestações criança ODONTO } \\
\text { Retirada de atenção (ATEN) FONO } \\
\text { Restrição A ODONTO } \\
\text { Restrição B ODONTO } \\
\text { Restrição C ODONTO } \\
\text { Restrição (genérica) FONo } \\
\text { Redução de mobilidade (M OB) } \\
\text { FONO }\end{array}$ \\
\hline Distrativas (DISTR) & Distração ODONTO & \\
\hline $\begin{array}{l}\text { Alterações na } \\
\text { estratégia inicialmente } \\
\text { planejada (ALT) }\end{array}$ & $\begin{array}{l}\text { Divisão da responsabilidade / Fuga da situação (FUGA) } \\
\text { FONo + ODonto } \\
\text { Mudança de procedimento odontológico (MP) } \\
\text { M ODONTança de estratégia (ME) } \\
\text { Autorização da presença da mãe (AUT. MÃE) } \\
\text { Mono } \\
\text { Modelo de terapeuta experiente (MODELO) }\end{array}$ & \\
\hline Outros (OT) & $\begin{array}{l}\text { Expressão de sentimentos sobre as dificuldades (SS) } \\
\text { Explicitação da criação de vínculo (VINC) } \\
\text { Fono }\end{array}$ & \\
\hline
\end{tabular}


mandos (abrir a boca, tirar a mão, manter-se em certa posição). Na Fonoaudiologia, as ordens específicas tendem a ser consideradas como parte da atuação do profissional depois que a criança passa a colaborar/participar do tratamento, e não como forma de iniciar essa colaboração.

* subcategorias I nespecífica e Restrição A eB, da categoria Restrição: na Fonoaudiologia não há a necessidade do uso de abridores de boca, nem de mudanças na postura da criança no momento imediato, eas ações restritivas são mais verbais.

* categoria Distração: na Fonoaudiologia há a necessidade de interação profissional-paciente o tempo todo, os procedimentos dependem dessa interação enão podem ser realizados somente pelo profissional, assim o foco da criança precisa ser a atividade. Não se aplica a estratégia de tirar o foco da atenção da criança para o tratamento, como no caso do atendimento odontológico.

* categoria I gnorar as ações da criança: pelo motivo exposto no item anterior.

* categoria Mudança de procedimento odontológico: essa categoria foi adaptada para Mudança de estratégia na Fonoaudiologia, para dar ênfase ao fato de que o objetivo do tratamento é mantido, e se muda a estratégia, respeitando os interesses da criança.

- Categorias incluídas:

* Representação/demonstração: execução do movimento em diferentes sujeitos (ex.: executar o procedimento na terapeuta, no fantochee na criança em frente ao espelho), de forma a explicitálo para a criança e motivá-la para a participação.

* Tentativa de convencimento: tentar convencer a criança a permanecer colaborando (ex.: "é cedo, vamos brincar mais").

* Estratégia lúdica: propor-se a utilizar uma atividade/ação mais lúdica que a planejada inicialmente.

* Encorajamento da cooperação (no atendimento em grupo): propor a execução da atividade em conjunto, para uma construção coletiva.

* Retirada de atenção: propor-se a continuar a atividade sem a criança quando ela se recusar a participar.

* Redução de mobilidade: reduzir as possibilidades de movimentação da criança na sala (ex.: "manter a criança no canto da sala", colocar-se, ou colocar objetos, entre a criança e a porta).

* Mudança de estratégia: mantido o objetivo, muda-se/adapta-se a estratégia, com foco nos interesses/preferências/possibilidades da criança.
* Autorização da presença da mãe: deixar a mãe entrar junto no atendimento, diante da recusa da criança entrar sozinha, tentando, depois, afastá-la, às vezes gradualmente.

* M odelo deterapeuta experiente: entrada da supervisora no atendimento, como modelo para as próximas ações do estagiário.

* Explicitação de criação de vínculo: explicitar intenção de criação de vínculo com a criança ao propor uma atividade específica, mesmo deixando em plano secundário o objetivo específico da sessão.

As mudanças verificadas entre os sistemas de categorias do estudo da Odontologia e do estudo da Fonoaudiologia apontam para diferenças e especificidades na atuação de cada profissão. Essas diferenças e especificidades foram observadas em alguns aspectos como: a) a urgência do procedimento, b) a colaboração esperada da criança, ec) a periodicidade da intervenção.

a) Quanto à urgência do procedimento, na O dontologia, a não-realização do procedimento pode ocasionar em problemas imediatos, como no caso de quadros de infecção severa e dores agudas. Além disso, uma vez iniciado um procedimento, como, por exemplo, o preparo cavitário, este precisa ser concluído. Já na Fonoaudiologia, a não-realização do procedimento não gera consequência negativa imediata.

b) Quanto à colaboração esperada da criança, na O dontologia é esperado quea criança permita a real ização do procedimento, permanecendo nas posições solicitadas pelo tempo necessário. Já no caso da Fonoaudiologia, os atendimentos envolvem a manutenção de interação e a realização de atividades propostas pelo profissional.

c) Quanto à periodicidade da intervenção, de forma geral, os atendimentos odontológicos envolvem uma ou mais sessões, seguidas por um grandeinterval o de tempo (entre seis meses eum ano) entre os atendimentos. Já os atendimentos fonoaudiológicos tendem a ser programados para ocorrer uma ou duas vezes por semana, por um período de tempo geralmente prolongado (medido em meses ou anos).

Essas diferenças foram evidenciadas a partir da comparação entre os dois sistemas de categorias, e a partir da análise das rotinas de atendimento nas duas profissões. 
Organização deum panorama das situações que trazem mais dificuldade

no atendimento fonoaudiológico;

e levantamento da origem das estratégias

utilizadas diante de situações de

não-colaboração no

atendimento fonoaudiológico

Os Quadros 2, 3 e 4 apresentam os dados obtidos a partir das respostas dos estudantes, respectivamente para as áreas deAudiologia, Linguagem, e M otricidade Orofacial/Voz.

No Q uadro 2, é possível observar que foram encontradas respostas classificadas em categorias do tipo Persuasivas, Restritivas eAlterações na Estratégia Inicialmente Planejada. No tipo Persuasivas, apareceram as categorias Tranquilização e Estratégia Lúdica, já no tipo Restritivas, apareceu somente a categoria Restrição, eno tipo Alterações na Estratégia Inicialmente Planejada, apareceram as categorias M udança de Estratégia e Fuga. Também é possível observar que o foco dos problemas nesse tipo de atendimento éa criança se recusar a responder ao exame. $\mathrm{Na}$ área de Audiologia, não foram relatadas estratégias originadas de orientações de professores, prevalecendo estratégias originadas de experiências pessoais e de colegas.

No Quadro 3, é possível observar que foram encontradas respostas específicas em todos os tipos de categorias disponíveis nesse sistema. Sendo assim, a área da Linguagem apresentou um maior número de relatos, e, também, uma maior gama de estratégias abarcadas. Da mesma forma, é possível observar que os problemas nesse tipo de atendimento são mais variados, desde a criança não querer se afastar da mãe até não querer fazer a atividade proposta. $\mathrm{N}$ a área de Linguagem, foram relatadas estratégias originadas de orientações de professores, de experiências pessoais e de colegas.

No Quadro 4, é possível observar que foram encontradas respostas específicas em todos os tipos de categorias do sistema. Da mesma forma, é possível observar que os problemas nesse tipo de atendimento são variados, mas o foco éa criança ter medo do atendimento. $\mathrm{N}$ as áreas de M otricidade O rofacial e Voz foram relatadas estratégias originadas de orientações de professores, de experiências pessoais e de colegas.

Quadro 2. M odos de lidar com situações de não colaboração/participação no atendimento em Audiologia.

\begin{tabular}{|c|c|c|c|c|}
\hline Tipo & $\begin{array}{c}\text { Categorias/ } \\
\text { Subcategorias }\end{array}$ & Problema & Estratégia - exemplos & Origem * \\
\hline \multicolumn{5}{|l|}{ INSTR } \\
\hline PERS & $\begin{array}{l}\text { TRANQ } \\
\text { ESTR } \\
\text { LÚDICA }\end{array}$ & $\begin{array}{l}\text { a criança não responde. } \\
\text { a criança não quer } \\
\text { fazer, começa a chorar }\end{array}$ & $\begin{array}{l}\text { "Tentar perguntar de coisas que } \\
\text { fossem do cotidiano dela, tentar } \\
\text { entender um pouco pra ver se tinha } \\
\text { alguma coisa que ela gostasse que } \\
\text { chamasse a atenção dela"; } \\
\text { "conversamos" } \\
\text { "tornar a situação mais lúdica", "a } \\
\text { gente tentou condicionar com } \\
\text { brinquedo" }\end{array}$ & EST / COL \\
\hline RESTR & REST & $\begin{array}{l}\text { criança não quer fazer } \\
\text { o exame, chora. }\end{array}$ & $\begin{array}{l}\text { "a tia segurava ela para a gente poder } \\
\text { fazer" }\end{array}$ & EST \\
\hline ALT & ME & $\begin{array}{l}\text { a criança não responde, } \\
\text { a criança não deixa } \\
\text { colocar a sonda, mãe } \\
\text { agitada. }\end{array}$ & $\begin{array}{l}\text { "Aí a gente saiu, deu uma volta", "você } \\
\text { pegar algo que a criança se interesse e } \\
\text { associar o estimulo ao brinquedo", } \\
\text { "pegar alguns brinquedos diferentes } \\
\text { que pudessem atraí-la”, “levar a } \\
\text { criança para beber água” }\end{array}$ & EST / COL \\
\hline OT & FUGA & $\begin{array}{l}\text { a criança não quer } \\
\text { fazer o exame, chora. }\end{array}$ & "teve que remarcar" & EST \\
\hline
\end{tabular}


Quadro 3. M odos de lidar com situações de não colaboração/participação no atendimento em Linguagem.

\begin{tabular}{|c|c|c|c|c|}
\hline Tipo & $\begin{array}{c}\text { Categorias/ } \\
\text { Subcategorias }\end{array}$ & Problema & Estratégia - exemplos & Origem * \\
\hline INSTR & EXPL & $\begin{array}{l}\text { "ela não queria fazer de jeito } \\
\text { nenhum e então ela ficava } \\
\text { buscando outras coisas na sala" }\end{array}$ & $\begin{array}{l}\text { "eu falava assim: 'não, vamos fazer aqui, } \\
\text { olha só , olha a figurinha, olha uma coisa } \\
\text { que a gente fez semana passada você } \\
\text { lembra? O uvir música.",; 'toda vez } \\
\text { conversar com ela antes do atendimento, } \\
\text { antes de começar, agente entrava na sala e } \\
\text { antes de pegar qualquer atividade, todo dia } \\
\text { eu falava a mesma coisa” }\end{array}$ & EST \\
\hline PERS & $\begin{array}{l}\text { TRANQ } \\
\text { CONV } \\
\text { ESTR } \\
\text { LÚDICA } \\
\text { CONT } \\
\text { OF } \\
\text { COOP }\end{array}$ & $\begin{array}{l}\text { a criança não quer fazer a } \\
\text { atividade, não quer entrar na sala, } \\
\text { chora. } \\
\text { a criança fica procurando outras } \\
\text { coisas na sala. } \\
\text { a criança não quer fazer a } \\
\text { atividade. } \\
\text { a criança quer ficar com a mãe. } \\
\text { a criança não faz o que a terapeuta } \\
\text { pede. } \\
\text { "eles competiam" }\end{array}$ & $\begin{array}{l}\text { interagir com a criança; conversar; abaixar } \\
\text { na mesma altura da criança. } \\
\text { "Daí eu converso com ela, falo: olha, é } \\
\text { cedo vamos brincar mais um pouquinho e } \\
\text { tal" } \\
\text { tentar ser mais lúdica; "faz uma atividade } \\
\text { mais animada". } \\
\text { "fazer com que ela passe a ter mais voz } \\
\text { na terapia” } \\
\text { negociação (colocação de regras no jogo } \\
\text { que a criança quer jogar). } \\
\text { "fazer eles construírem coisas em } \\
\text { conjunto" }\end{array}$ & $\begin{array}{l}\text { EST / COL } \\
\text { / PROF } \\
\text { EST } \\
\text { EST / } \\
\text { PROF } \\
\text { PROF } \\
\text { EST } \\
\text { PROF }\end{array}$ \\
\hline RESTR & $\begin{array}{l}\text { ATEN } \\
\text { CENS }\end{array}$ & $\begin{array}{l}\text { a criança não quer fazer a } \\
\text { atividade. } \\
\text { a criança convencendo as outras } \\
\text { do grupo a não fazer a atividade; a } \\
\text { criança não quer fazer a atividade. } \\
\text { a criança convencendo as outras } \\
\text { do grupo a não fazer a atividade; a } \\
\text { criança não quer fazer a atividade. } \\
\text { "não conseguiam manter a criança } \\
\text { dentro da sala de atendimento" }\end{array}$ & $\begin{array}{l}\text { fazer a atividade sem a criança. } \\
\text { "a gente chamava a atenção mesmo, era } \\
\text { meio brava"; "A hora que ele voltar } \\
\text { também, não deixa ele entrar direto na } \\
\text { brincadeira, já que ele não queria fazer } \\
\text { então agora ele vai ter que esperar." } \\
\text { "ser mais firme assim com elas e falar com } \\
\text { mais rigidez; "Se você não voltar você vai } \\
\text { ficar sem fazer e a gente vai continuar } \\
\text { fazendo dos outros" } \\
\text { "colocar a criança sentada entre os cantos } \\
\text { da sala e olha de frente para a criança" }\end{array}$ & $\begin{array}{l}\text { EST / } \\
\text { PROF } \\
\text { EST / } \\
\text { PROF }\end{array}$ \\
\hline ALT & $\begin{array}{l}\text { FUGA } \\
\text { MODELO } \\
\text { AUT. M ÃE }\end{array}$ & $\begin{array}{l}\text { a criança saí correndo para não } \\
\text { entrar na sala. } \\
\text { a criança se nega a fazer a atividade. } \\
\text { a criança quer ficar com a mãe. }\end{array}$ & $\begin{array}{l}\text { "A gente tentou usar jogo"; “trazer o } \\
\text { brinquedo que ela mais gostava”; “eu } \\
\text { tentava criar uma situação que ele gostava, } \\
\text { pra eu desenvolver o que eu queria com } \\
\text { ele."; "pegar coisas que interessavam a ele”; } \\
\text { "faz a brincadeira parecer mais } \\
\text { interessante para prender a atenção, para } \\
\text { ela ficar lá dento da sala. Ou então quando } \\
\text { não tinha jeito e ela queria sair, eu saia } \\
\text { dava uma volta."; mudar a atividade } \\
\text { "não ia dar para fazer nada naquele dia” } \\
\text { "a supervisora entrava comigo no começo" } \\
\text { deixar a mãe entrar na sala. }\end{array}$ & $\begin{array}{l}\text { PROF } \\
\text { EST / COL } \\
\text { / PROF } \\
\text { PROF }\end{array}$ \\
\hline OT & VINC & criança rotulada como difícil. & criar vínculo com a criança. & PROF \\
\hline
\end{tabular}


Quadro 4. M odos de lidar com situações de não colaboração/participação no atendimento em M otricidade Orofacial e Voz.

\begin{tabular}{|c|c|c|c|c|}
\hline Tipo & $\begin{array}{c}\text { Categorias / } \\
\text { Subcategorias }\end{array}$ & Problema & Estratégia - exemplos & Origem * \\
\hline INSTR & REPRES & criança com medo. & $\begin{array}{l}\text { fazer o procedimento no fantoche, } \\
\text { na terapeuta e com espelho. }\end{array}$ & $\begin{array}{l}\text { EST / } \\
\text { PROF }\end{array}$ \\
\hline \multirow[t]{3}{*}{ PERS } & TRANQ & $\begin{array}{l}\text { criança faz a atividade } \\
\text { desanimada; criança } \\
\text { com medo. }\end{array}$ & $\begin{array}{l}\text { conversar; fazer perguntas; mostrar } \\
\text { para a criança que não vai fazer mal a } \\
\text { ela e que pode confiar na terapeuta; } \\
\text { esperar o tempo da criança. }\end{array}$ & EST / COL \\
\hline & $\begin{array}{l}\text { ESTR } \\
\text { LÚDICA }\end{array}$ & $\begin{array}{l}\text { criança tem medo; } \\
\text { criança não consegue } \\
\text { fazer os exercícios. }\end{array}$ & $\begin{array}{l}\text { "fazer uma coisa bem mais lúdica”; } \\
\text { "tentar por meio de brincadeira”. }\end{array}$ & $\begin{array}{l}\text { COL / } \\
\text { PROF }\end{array}$ \\
\hline & OF & $\begin{array}{l}\text { criança subindo na } \\
\text { cadeira, gritando. }\end{array}$ & $\begin{array}{l}\text { "eles tinham que obedecer para a } \\
\text { gente poder jogar o jogo que eles } \\
\text { queriam" }\end{array}$ & EST \\
\hline RESTR & $\begin{array}{l}\text { CENS } \\
\text { AM }\end{array}$ & $\begin{array}{l}\text { criança subindo na } \\
\text { cadeira e gritando. } \\
\text { criança subindo na } \\
\text { cadeira e gritando. }\end{array}$ & $\begin{array}{l}\text { chamar a atenção deles. } \\
\text { "explicar sobre as pregas vocais, para } \\
\text { eles não gritarem" }\end{array}$ & $\begin{array}{l}\text { EST } \\
\text { EST }\end{array}$ \\
\hline ALT & AUT. M ÃE & $\begin{array}{l}\text { criança só entra com a } \\
\text { mãe. } \\
\text { criança com medo; } \\
\text { criança não consegue } \\
\text { fazer os exercícios. }\end{array}$ & $\begin{array}{l}\text { deixar a mãe entrar na sala; } \\
\text { "estratégia de levar a mãe para o } \\
\text { atendimento e da mãe ter que } \\
\text { participar de uma parte do } \\
\text { atendimento junto e depois a mãe } \\
\text { saia, até ele se adaptar com o } \\
\text { estagiário" } \\
\text { mudança de procedimento. }\end{array}$ & EST / COL \\
\hline OT & VINC & criança com medo. & criar vínculo com a criança. & EST / COL \\
\hline
\end{tabular}

No Quadro 5 são apresentados os dados obtidos a partir das respostas dos docentes, respectivamente para as áreas de Audiologia, Linguagem, e M otricidade O rofacial e Voz.

No Quadro 5, é possível observar que alguns aspectos são elencados nos relatos de docentes de diferentes áreas. Em relação às situações difíceis, os docentes relatam que o medo da criança frenteao atendimento, o histórico deatendimentos em saúde, a presença de alterações concomitantes e a relação da família com a criança e com 0 atendimento são fatores que influenciam na colaboração/participação da criança no atendimento fonoaudiológico.
Já em relação às soluções propostas, a criação de vínculo com a criança e com a família é relatada por todos os docentes entrevistados. 0 respeito à individualidade da criança, a necessidade de fornecimento de informações para a criança e a criação de situações lúdicas apareceram como aspectos relevantes na solução de problemas no atendimento fonoaudiológico.

\section{Discussão}

As mudanças na relação profissional-paciente, relacionadas com a humanização, fazem emergir 
Quadro 5. M odos de lidar com situações de não colaboração/participação no atendimento relatados pelos docentes das diferentes áreas da Fonoaudiologia.

\begin{tabular}{|c|c|c|c|}
\hline & Audiologia & Linguagem & MO / Voz \\
\hline $\begin{array}{l}\text { Situaçães difíceis } \\
\text { criança com medo } \\
\text { criança que passou por hospitalização anterior ou atendimentos } \\
\text { traumáticos } \\
\text { criança com alterações concomitantes } \\
\text { criança muito nova } \\
\text { criança cansada } \\
\text { criança que não quer ficar sem a mãe } \\
\text { criança que desconhece ou não entende o que vai ser realizado } \\
\text { criança que tem ganhos sociais com a queixa } \\
\text { criança que não lida bem com limites } \\
\text { criança influenciada por questões familiares (nascimento de } \\
\text { irmãos, não adesão da família ao tratamento) } \\
\text { estranhamento da situação, no inicio do tratamento }\end{array}$ & $\begin{array}{l}x \\
x \\
x \\
x\end{array}$ & $x$ & $\begin{array}{l}\mathrm{x} \\
\mathrm{x} \\
\mathrm{x} \\
\mathrm{x} \\
\mathrm{x} \\
\mathrm{x} \\
\mathrm{x} \\
\mathrm{x} \\
\mathrm{x}\end{array}$ \\
\hline $\begin{array}{l}\text { Soluções propostas / Orientações } \\
\text { explicar o que vai acontecer } \\
\text { deixar a criança explorar o ambiente e os aparelhos } \\
\text { construir situação lúdica } \\
\text { preparar diferentes possibilidades para alcançar objetivos do } \\
\text { atendimento } \\
\text { criar vínculo com a criança e/ou com o acompanhante } \\
\text { ingresso gradativo nas terapias / respeitar o tempo da criança } \\
\text { entendimento da origem do problema }\end{array}$ & $\begin{array}{l}x \\
x \\
x \\
x \\
x\end{array}$ & $\begin{array}{l}x \\
x \\
x\end{array}$ & $\begin{array}{l}x \\
x \\
x\end{array}$ \\
\hline
\end{tabular}

os conceitos de "colaboração" e "participação" do paciente no seu próprio atendimento. Esses conceitos são diferentes, trazendo implicações distintas na relação do paciente edo profissional com 0 atendimento eo outro, sendo o nível de comprometimento com 0 atendimento em saúde maior na "participação" do que na "colaboração"

Diante das diferenças entre as estratégias re latadas pelos estudantes de Fonoaudiologia e as do estudo com estudantes de Odontologia, foi possível perceber que o trabalho fonoaudiológico envolve uma participação ativa da criança, enquanto o trabal ho odontológico pode ser realizado quando existe colaboração da criança. Dessa forma, no atendimento fonoaudiológico, surge a necessidade de atenção para a individualidade de cada paciente, de forma a estabelecer interações que envolvam participação ativa.

A relação profissional-paciente ${ }^{16-19}$ é referida na literatura em saúde como uma relação delica$\mathrm{da}$, que requer uma visão diferenciada do profissional frente ao seu cliente, exigindo queseja preparado durante a graduação tendo em vista a peculiaridade dessa relação. A importância do respeito à individualidade de cada paciente e a necessidade dos profissionais de saúde abrirem espaço para o paciente opinar sobre seu problema e sobre suas expectativas aparecem na literatura ${ }^{16,20,21}$. É possível observar essa preocupação nas respostas dos sujeitos desse estudo, quando eles se propõem a investigar as preferências da criança e a planejar suas atividades de acordo com os interesses dela.

Os medos e os anseios frente aos estágios supervisionados do curso de Fonoaudiologia ${ }^{10}$ apareceram no relato de alguns estudantes do presente estudo, e evidenciam a importância de haver maior interesse por pesquisas que abordem essa questão.

Alguns pontos chamaram a atenção nos relatos dos estudantes de Fonoaudiologia, especialmente a preocupação com o paciente como um sujeito que tem que ser cuidado na sua totalidade. Esses relatos evidenciam a incorporação de conceitos importantes que propiciam um atendimento fonoaudiológico humanizado. 
A humanização $22-25$ é um tema que traz uma discussão ideológica e política, visto que exige mudanças sociais e individuais para ser uma realidade nos serviços de saúde. 0 conceito de humanização tem uma relação direta com a relação profissional-paciente, ao sugerir que essa relação seja a mais simétrica que for possível.

A área de Linguagem, entre as da Fonoaudiologia, foi aquela que apresentou maior gama de relatos de situações difíceis e de soluções encontradas, evidenciando que a colaboração/participação do paciente não está relacionada somente à real ização de procedimentos específicos, como são os testes e exercícios das outras áreas.

Comparando as respostas dos estudantes e as respostas dos docentes do presente estudo, foi possível observar que as estratégias relatadas pelos estudantes apresentavam relação com as descritas pelos docentes. Dessa forma, pode-se pensar que as utilizadas pel os estudantes podem ter origem naquelas utilizadas e recomendadas por seus supervisores.

\section{Conclusão}

0 estudo permitiu o aprofundamento da intersecção das estratégias e modos de ação que buscam obter colaboração/participação da criança no atendimento, com a questão da relação profissional-paciente e a questão da humanização. A partir disso, foi permitido refletir sobre a importância que deve ser dada a essas questões na formação dos profissionais de saúde, especialmente no que se refere à Fonoaudiologia, que apresenta carência de trabalhos nessa área.

Os resultados também apontaram situações que mais trazem dificuldade para os profissionais no atendimento fonoaudiológico, além de possibilitarem um mapeamento das estratégias utilizadas diante dessas situações. Dessa forma, o estudo contribuiu para um aprimoramento do conhecimento nessa área, o que podelevar a uma melhor qualidade no atendimento, beneficiando clientes e profissionais.

\section{Colaboradores}

Todos os autores atuaram na concepção e na elaboração final do trabalho. CL N ascimento realizou a coleta e análise de dados, sob supervisão de CG Batista. A equipe de pesquisa, composta por CL N ascimento, CG Batista, GS Rolim e ABA M oraes, participou da elaboração do projeto, da discussão dos dados e da redação final do projeto.

\section{Agradecimentos}

À FAPESP pelo financiamento da pesquisa. 


\section{Referências}

1. Sahlsten MJM, Larsson IE, Sjöström B, Plos KAE. An Analysis of the Concept of Patient Participation. Nursing Forum 2008; 43(1):2-11.

2. Perosa GB, Gabarra LM, Bossolan RP, Ranzani PM, Pereira VM. Aspectos psicológicos na comunicação médico-paciente no setting pediátrico. In: Crepaldi MA, Linhares MBM, Perosa GB, organizadores. Temas em Psicologia Pediátrica. São Paulo: Casa do Psicólogo; 2006. p. 57-82

3. Singh Sánchez KA. U ma descrição funcional do comportamento do cirurgião-dentista no contexto de sua atuação profissional [tese]. Araraquara: Faculdade de Odontologia de Araraquara da Universidade do Estado de São Paulo; 2001.

4. Sarnat H, Arad P, Hanauer D, Shohami E. Communication strategies used during pediatric dental treatment: a pilot study. Pediatr Dent 2001; 23(3):337-342

5. Cardoso CL. Tratamento odontopediátrico no contexto de uma clínica-escola: avaliação do estresse da criança, do acompanhante e do aluno [tese]. Ribeirão Preto: Faculdade de Filosofia, Ciências e Letras de Ribeirão Preto; 2002.

6. Possobon RF, Moraes ABA, Costa Jr AL, Bovi Ambrosano GM. O Comportamento de Crianças Durante Atendimento Odontológico. Psicologia: Teoria e Pesquisa 2003; 19(1):59-64.

7. Moraes ABA, Possobon RF, Costa Jr AL, Mesquita e Fonseca CM, Silva ARC, Rolim GS. A psicologia pediátrica aplicada à odontologia. In: Crepaldi MA, Linhares M BM, Perosa GB, organizadores. Temas em Psicologia Pediátrica. São Paulo: Casa do Psicólogo; 2006.

8. Nascimento $C L$, Batista CG, Rolim GS, Ambrosano GMB, Rocha RASS, Rodrigues AFP, Moraes ABA. Student self-confidence in coping with uncooperative behaviors in pediatric dentistry. Artigo submetido ao European Journal of Dental Education; 2009.

9. Cupello RMC. A relação terapeuta paciente em Fonoaudiologia. Rio de Janeiro: Ed. Revinter; 1995.

10. Martins M CFN. A Transição Estudante-Fonoaudiológo: Estudo Qualitativo sobre a Vivência dos primeiro Atendimentos [tese]. São Paulo: Escola Paulista de Medicina; 1998.

11. Ferraz MCA. M anual Prático de M otricidade Oral: Avaliação e Tratamento. 5a ed. Rio de Janeiro: Editora Revinter; 2001.

12. Behlau M. Voz: O Livro do Especialista. Vol. 2. Rio de Janeiro: Editora Revinter; 2005.

13. Northern JL, Downs MP. Avaliação Auditiva Comportamental. In: Northern JL, D owns M P. Audição na Infância. 5a ed. Rio de Janeiro: Editora Guanabara Koogan; 2005.

14. Widen JE, Gwendolyn MO. Using visual reinforcement audiometry in the assessment of hearing in infants. Hearing Journal 2002; 55(11):28-36.
15. Bardin L. Análise de Conteúdo. Coimbra: Edições 70; 2008.

16. Harrington J, Noble LM, Newman SP. Improving patients' communication with doctors: a systematic review of intervention studies. Patient Educ Couns 2004; 52(1):7-16.

17. Ferguson WJ, Candib LM. Culture, Language, and the Doctor-Patient Relationship. Fam M ed 2002; 34(5):353-361.

18. Ackermana SJ, Hilsenrothb MJ. A review of therapist characteristics and techniques positively impacting the therapeutic alliance. Clin Psychol Rev. 2003; 23(1):1-33.

19. Caprara A, Rodrigues J. A relação assimétrica médico-paciente: repensando o vínculo terapêutico. Cien Saude Colet 2004; 9(1):139-146.

20. Eldh AC, Ekman I, Ehnfors M. Conditions for Patient Participation and Non-participation in health care. Nurs Ethics 2006; 13(5):503-514.

21. Fraenkel L, McGraw S. What are the Essential Elements to Enable Patient Participation in Medical Decision M aking? J Gen Intern M ed 2007; 22(5):614619.

22. Goulart BNG de, Chiari BM. Avaliação clínica fonoaudiológica, integralidade e humanização: perspectivas gerais e contribuições para reflexão. Rev Soc Bras Fonoaudiol. 2007; 12(4):335-340.

23. Puccini PT, Cecílio LCO. A humanização dos serviços e o direito à saúde. Cad Saude Publica 2004; 20(5):1342-1353.

24. Brasil. Ministério da Saúde. Política Nacional de Humanização. [acessado 2006 fev 5]. Disponível em: http://portal.saude.gov.br/saude/area.cfm?id_ area $=390 ; 2004$

25. Campos GWS. Humanização na saúde: um projeto em defesa da vida? Interface 2005; 9(17):398-400.
Artigo apresentado em 08/04/2010

Aprovado em 12/07/2010

Versão final apresentada em 20/07/2010 